\title{
Design of a conductive material detection system
}

\author{
Freddy Artadima Silaban, Setiyo Budiyanto, Lukman Medriavin Silalahi \\ Department of Electrical Engineering, Universitas Mercu Buana, Indonesia
}

\begin{tabular}{l} 
Article Info \\
\hline Article history: \\
Received Jun 30, 2020 \\
Revised Sep 13, 2020 \\
Accepted Sep 22, 2020 \\
\hline
\end{tabular}

\section{Keywords:}

ADC

Arduino

Blynk Server

Conductive material

ESP8266

\begin{abstract}
The development of technology and industry development in the 4.0 era is very fast along with these developments in the control of production results such as medicine, food, and safety must be faster and more accurate. To face free trade and global economic competition, every company is required to produce products that have good quality by the standards. By using an experimental method which is the development of this study aims to make a conductive material detector (metal detector) for the pharmaceutical industry, the food industry, and security as compared to using conductive material sensors that are integrated with the Arduino microcontroller. Application testing is carried out to find out whether the Blynk application on an android smartphone with Blynk on a Debian server that has been made previously runs well or not and the alarm system testing uses a buzzer and LED to detect conductive material passing through. Conductive sensor test results showed that the instrument can detect 6 conductivity materials such as stainless steel, aluminum, steel, zinc, copper, and tin. The average response time to detect conductive material is 3 seconds, the average ADC value of the conductive material is 0.55 . The test results also successfully send information and data to the Blynk application so that it can be monitored online.
\end{abstract}

This is an open access article under the CC BY-SA license.

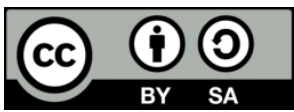

Corresponding Author:

Freddy Artadima Silaban,

Department of Electrical Engineering,

Universitas Mercu Buana,

Meruya Selatan, Kembangan, Jakarta Barat 11650, Indonesia.

Email: freddy.artadima@mercubuana.ac.id

\section{INTRODUCTION}

Supervision in various fields requires a supporter who can do what cannot be done by humans, for example, in the fields of health, product quality, and safety. Health is an important thing that concerns the community. Medication becomes one of the important needs to maintain health and treat all diseases. One indicator in measuring the quality of medicines is to be free from conductive materials such as metals. If the drug contains metal, the health of the users deteriorates and the drug industry experiences a decline in consumers and decreases in company profits [1-5]. The quality of other products that must be considered such as food products such as ready-to-eat products, baby food, and other foods. Conductive material detection sensors are used for security such as in aircraft airports where before entering aircraft all objects that are attached or not attached to the human body must be removed if not removed then detected by the sensor [6-10].

In the world of the pharmaceutical industry and the food industry, several products are contaminated by conductive materials, either magnetic or non-magnetic. This is due to contamination from conductive materials (material contamination, mixing process errors, and machine failures) $[11,12]$ and the use of various equipment in the production process which is mostly made of conductive material. Detection of conductive material contamination in drugs and food is very important and requires high accuracy, thus 
conductive material detectors play an important role in ensuring product safety in the pharmaceutical industry [13-20].

So many things must be considered in the process of producing drugs and food to maintain the quality of the products produced. Therefore, in this study, the author tries to make a prototype of a conductive material detection device that is simple to produce better quality surveillance [21-25]. This prototype design integrates a conductive material sensor with an Arduino Pro Mini microcontroller. When drugs and food products pass through this device containing a conductive material, the alarm sounds and the light indicator lights up. Insecurity if the sensor detects the presence of conductive material, alar. The average response time to detect conductive material is 3 seconds, the average ADC value of the conductive material is 0.55. The test results also successfully send information and data to the Blynk application so that it can be monitored online.

\section{RESEARCH METHOD}

\subsection{General review}

This research is the design of a conductive material detection system. The system that will be created is a system used to detect conductive materials in the products of the drug-drug and food-food industry products that are contaminated with metals and become aids in security systems such as airports. With this system, it is possible to monitor production results such as medicinal products, contaminated foods that can be separated and destroyed because if it passes it will be dangerous for those who buy and use these medicinal products and foods.

The advantages of the system made in this study with similar products on the market are the price of tools and materials used cheaper, applications and supporting servers are free, besides Arduino-based microcontrollers that are integrated by Wi-Fi ESP8266 has features and specifications that make it possible to create or develop a bigger and better system.

In this design, two systems are made, namely the detection system and the monitoring system. In the monitoring system, the user uses the Blynk application to monitor the number of medicinal products and foods that are contaminated with metal in real-time. Whereas in the detection system, there is a sensor in the form of an electromagnetic coil that can detect grams of metal in drugs and food that will be separated using a servo motor to another container. In the security system, officers are also assisted in detecting anyone who carries conductive material.

When the system is turned on, the Arduino microcontroller performs a calibration on the detection sensor, then the device will connect to the server via a WIFI network that has registered its SSID, if the connection is successful then the microcontroller will be connected to the system server ready to use (online). If one process in the flowchart fails, it will display an error on the LCD screen and display it in the notification in the monitoring application.

\subsection{Research stages}

The block diagram for this research approaches the prototype tool, the design of the device that is built consists of several main hardware, including Arduino Pro Mini microcontroller and Wi-Fi Module ESP8266, as well as additional hardware to carry out the functions of the sensor input and output indicators namely metal sensor (coil winding), buzzer (alarm), and servo. The block diagram in Figure 1 is an initial illustration of the design of a conductive material detection system used which consists of an Arduino microcontroller, the conductive material sensor uses several turns, Blynk is used to monitor whether any conductive material is detected.

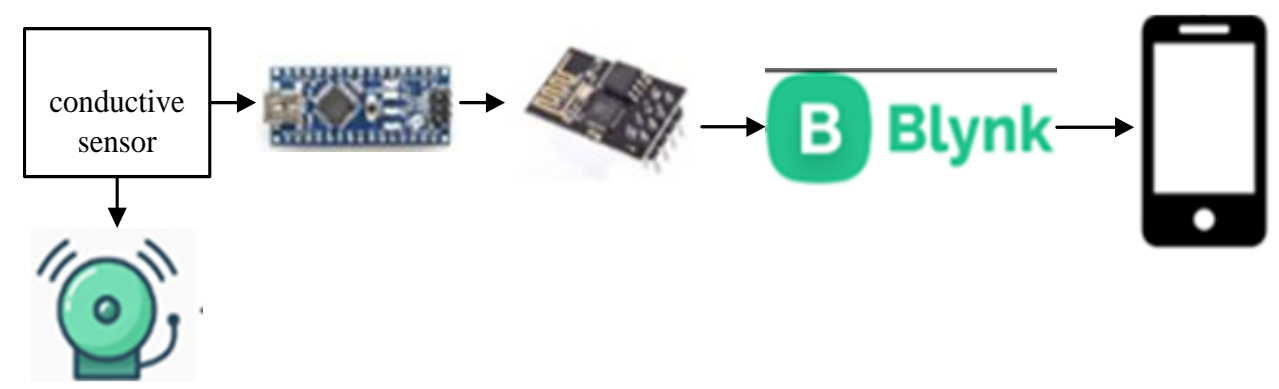

Figure 1. Block diagram of a conductive material detection system 


\subsection{Tool prototype design flow chart}

This flowchart explains the initial stages in the design and performance analysis of conductive material detection systems. Figure 2 illustrates the process of preparing a prototype tool where at first the controller must be configured with the internet, then configuring the conductive material detection sensor and conducting the conductive sensor calibration, the next is the testing of the conductive material which starts from the stainless steel test when a conductive material is detected "Then appear on the LCD and Blynk application Conductive Material”. If not, a second ingredient will be tested.

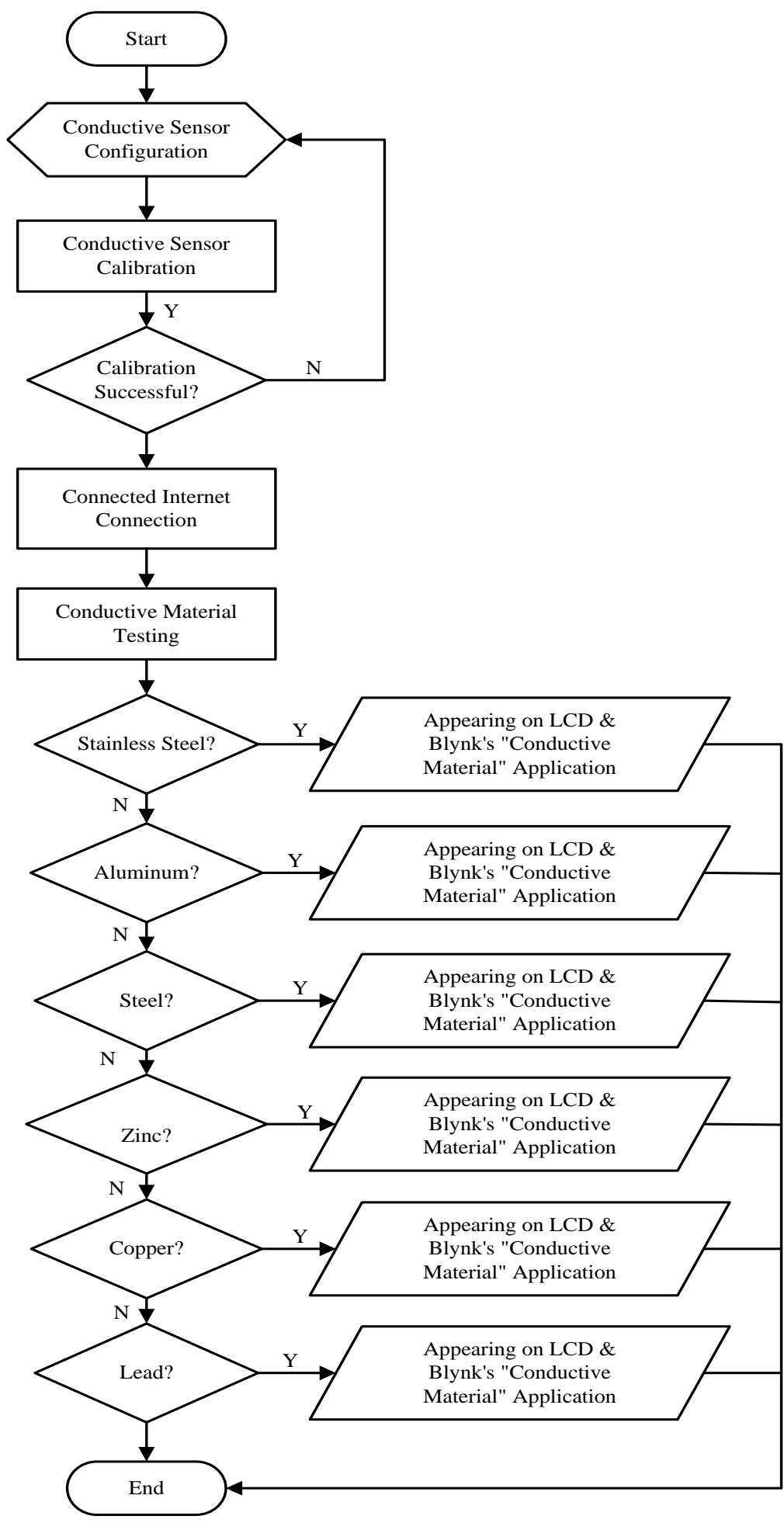

Figure 2. Design process flow chart

Int J Rob \& Autom, Vol. 9, No. 4, December 2020 : 292 - 299 
The second trial is aluminum when a conductive material is detected "Yes" then it appears on the LCD and Blynk application "Conductive Material". If not, a third ingredient will be tested. The third trial is steel when a conductive material is detected "Yes" then it appears on the LCD and Blynk application "Conductive Material". If not, the fourth ingredient will be tested. The fourth trial is zinc when a conductive material is detected "Yes" then it appears on the LCD and Blynk application "Conductive Material". If not, a fifth ingredient is tested. The fifth trial is copper if a conductive material is detected "Yes" then it will appear on the LCD and Blynk application "Conductive Material". If not, then a sixth material trial is conducted. The sixth trial is tin, if a "Yes" conductive material is detected, it will appear on the LCD and the "Conductive Material" Blynk application. If not, the trial is complete.

\subsection{Conductive material detection sensor circuit}

This metal sensor circuit serves to detect metal or metal objects that pass through the metal sensor. This circuit will emit electromagnetic waves constantly towards the area that will be the area of detection if objects other than metals that pass through the conductive sensor then the conductive sensor will detect any signal interference in the electromagnetic wave. See Figure 3.

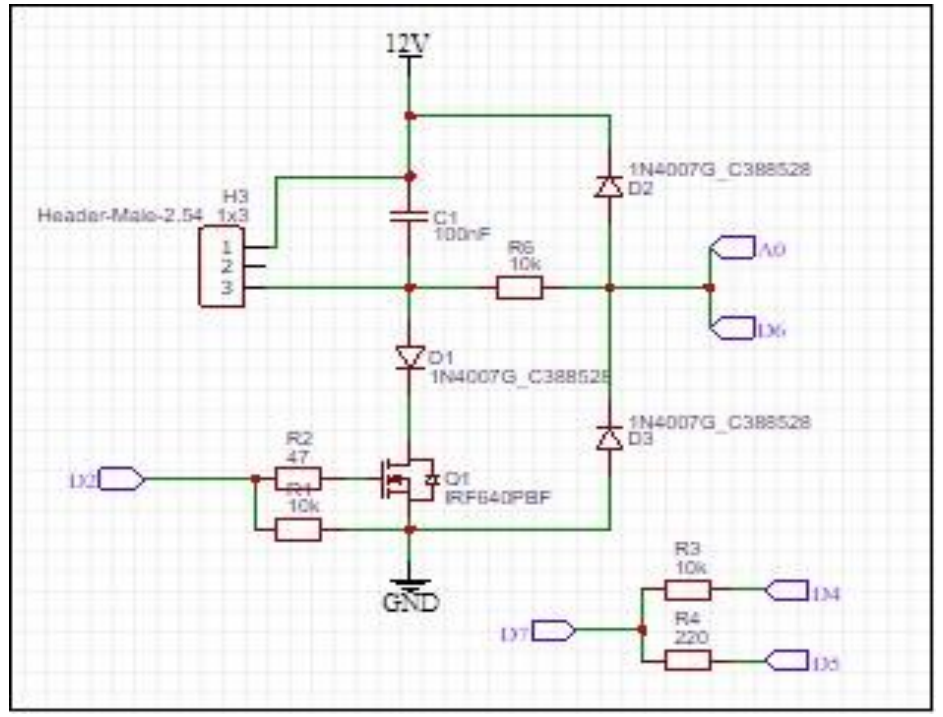

Figure 3. Conductive material detection circuit

\section{RESULTS AND DISCUSSIONS}

\subsection{Blynk application}

Blynk is an IoT Cloud platform for iOS and Android applications that is useful for controlling Arduino, Raspberry Pi, and similar boards via the internet. Blynk is a digital dashboard that can build a graphical interface for tools that have been created just by dragging and dropping a widget. Following are the steps for operating the Blynk application:

- Open the Blynk application then create a new account.

- Fill in the email and password then click the picture to set the server IP

- Move the position of the slider control to custom and fill in the IP along with the pre-set port, then click $\mathrm{OK} \rightarrow$ click sign up

- Then click the new project, then fill in the name of the project, select the device that corresponds to the device that was made, then select the connection type to be $\mathrm{Wi}-\mathrm{Fi} \_33$, click create.

- Then a message will appear informing you that the authentication code has been sent to the email address, click OK to finish creating the project.

\subsection{Header Program Code}

The \#include program code is a type of preprocessor driver that is used to read files called header files. iostream, conio.h, stdio.h, windows.h, math.h, and string.h are header files that are the standard library of $\mathrm{C}++$. Each header file is associated with input commands, output commands, and functions used in a program. The header program code is shown in Figure 4. 


\subsection{Blynk Server communication test results}

This test was carried out to find out how long it would take the Esp8266 microcontroller to communicate with the Blynk server. The time is calculated from the start of the device turned on until successfully communicating with the Blynk Server. If the LED indicator on the Esp8266 microcontroller is lit, that the Esp8266 microcontroller has successfully communicated with the server. The Arduino serial monitor shown in Figure 5 is what informs the server of communication.

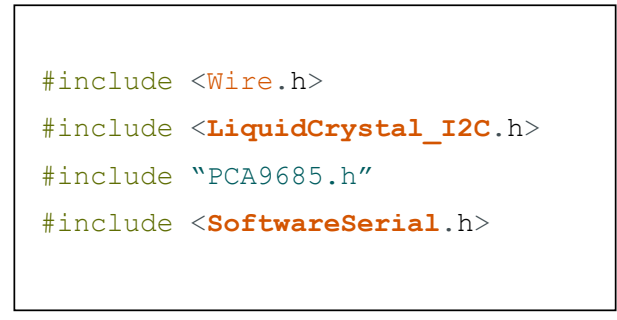

Figure 4. Header program code

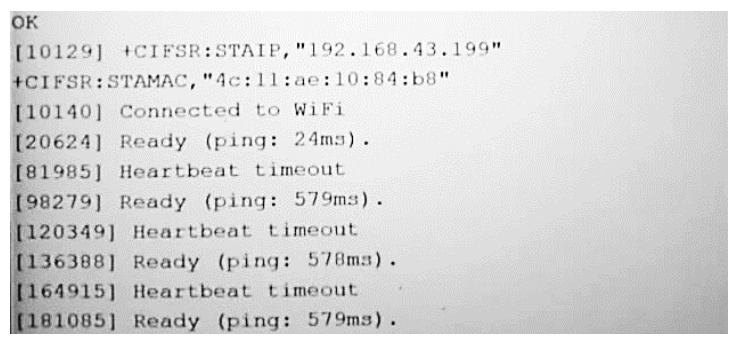

Figure 5. Serial monitor display

\subsection{Blynk application testing}

This test is carried out to determine the tools in this study work following the functions and desires. The testing process is done in stages through the Blynk application there are two control features in the application, namely the first feature for the sensor reading controller which is detected by the sensor and the second feature for calculating and displaying the detection results.

The main menu display of Figure 6 is information sent by the tool to the server so that it can see the amount detected by the metal detector, as in Table 1 is the response time to the metal sensor. The main menu display of Figure 6 is information sent by the tool to the server so that it can see the amount detected by the metal detector, as in Table 1 is the response time to the metal sensor. In Table 1, the average Alarm ON time required from the five trials is 2.10 seconds while for the average Alarm OFF is 2.30 seconds.

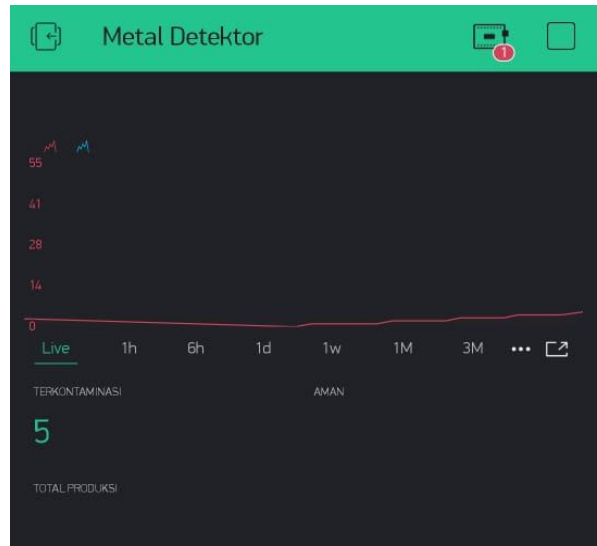

Figure 6. Initial display of Blynk
Table 1. Sensor response time testing

\begin{tabular}{cccc}
\hline Testing & Condition & Time (s) & Result \\
\hline \multirow{2}{*}{1} & Alarm On & 1.75 & Corresponding \\
& Alarm Off & 1.48 & \\
\multirow{2}{*}{2} & Alarm On & 2.71 & Corresponding \\
& Alarm Off & 2.72 & \\
\multirow{2}{*}{3} & Alarm On & 1.12 & Corresponding \\
& Alarm Off & 2.58 & \\
\multirow{2}{*}{4} & Alarm On & 1.23 & Corresponding \\
& Alarm Off & 1.78 & \\
\multirow{2}{*}{5} & Alarm On & 1,25 & Corresponding \\
& Alarm Off & 1,35 & \\
\hline
\end{tabular}

\subsection{Conductive sensor testing}

Conductive sensor testing that uses copper windings to detect objects made from passing with the ESP8266 microcontroller aims to find out how much the signal is read through the ADC value, can be seen in Table 2. Figure 7 is a conductive graph that has been detected by the sensor based on time in the last 6 hours.

\subsection{Testing for sending SMS Coordinate}

The purpose of testing the sending of SMS coordinator with Arduino is to find out if the program is made under what is desired and the program is under what was designed previously. For the results of testing the sensor response time to the sending of SMS coordinates can be seen in Table 3. From the results of the six experiments in Table 3, the average time required to send an SMS coordinate is 11.078 seconds. For SMS coordinates sent can be seen in the picture. 
Table 2. Conductive sensor testing

\begin{tabular}{ccccc}
\hline No & $\begin{array}{c}\text { Conductive } \\
\text { Material }\end{array}$ & $\begin{array}{c}\text { Time } \\
(\mathbf{s})\end{array}$ & $\begin{array}{c}\text { ADC } \\
\text { Value }\end{array}$ & Info \\
\hline 1 & Stainless Steel & 2,02 & 1,6 & Corresponding \\
2 & Aluminum & 4.15 & 0,1 & Corresponding \\
3 & Steel & 4,66 & 0,2 & Corresponding \\
4 & Zinc & 2,26 & 0,4 & Corresponding \\
5 & Copper & 2,12 & 0,6 & Corresponding \\
6 & Lead & 2,79 & 0,4 & Corresponding \\
\hline
\end{tabular}

Table 3. Coordinate delivery time testing

\begin{tabular}{ccccc}
\hline No & $\begin{array}{c}\text { Conductive } \\
\text { Material }\end{array}$ & Instruction & $\begin{array}{c}\text { Time } \\
(\mathbf{s})\end{array}$ & Result \\
\hline 1 & Stainless Steel & ON & 10,65 & Corresponding \\
2 & Aluminium & ON & 10,71 & Corresponding \\
3 & Steel & ON & 11,14 & Corresponding \\
4 & Zinc & ON & 11,30 & Corresponding \\
5 & Copper & ON & 11,59 & Corresponding \\
6 & Lead & ON & 12,10 & Corresponding \\
\hline
\end{tabular}

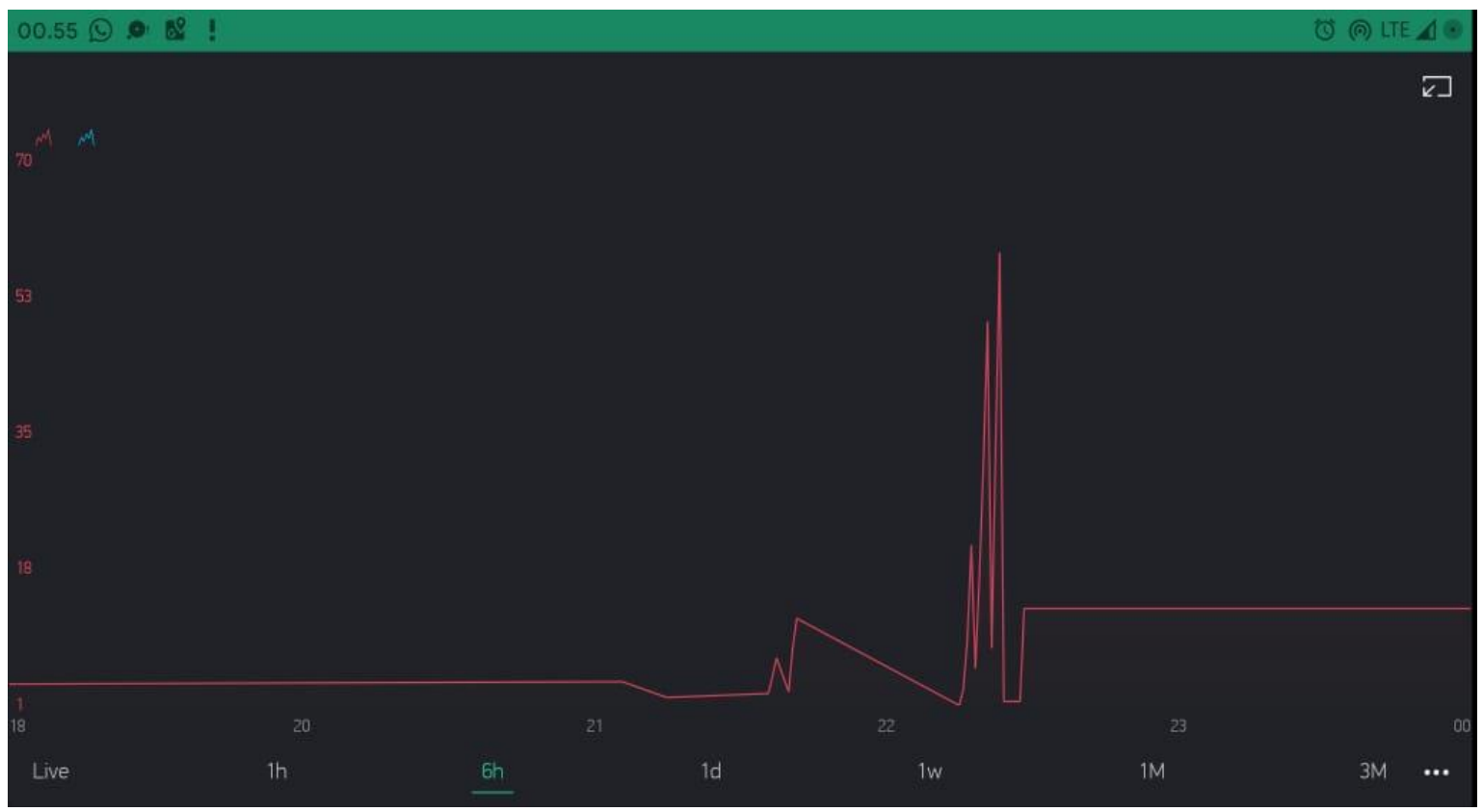

Figure 7. Graph of the number detected

\subsection{Prototype design results}

The following are the results of designing prototype devices for the detection of conductive. Figure 8 illustrates the process of preparing a prototype device which at first requires configuring the controller with the internet, then configuring the conductive material detection sensor and conducting the conductive sensor calibration, then testing the conductive material which starts from the stainless steel test when a conductive material is detected "Yes "Then appear on the LCD and Blynk application" Conductive Material ". If not, a second ingredient will be tested. The second trial is aluminum when a conductive material is detected "Yes" then it appears on the LCD and Blynk application "Conductive Material". If not, a third ingredient will be tested. The third trial is steel when a conductive material is detected "Yes" then it appears on the LCD and Blynk application "Conductive Material". If not, the fourth ingredient will be tested. The fourth trial is zinc when a conductive material is detected "Yes" then it appears on the LCD and Blynk application "Conductive Material". If not, a fifth ingredient is tested. The fifth trial is copper if a conductive material is detected "Yes" then it will appear on the LCD and Blynk application "Conductive Material". If not, then a sixth material trial is conducted. The sixth trial is tin, if a "Yes" conductive material is detected, it will appear on the LCD and the "Conductive Material" Blynk application. If not, the trial is complete.

\section{CONCLUSION}

Application testing is carried out to find out whether the Blynk application on an android smartphone with Blynk on a Debian server that has been made previously runs well or not and the alarm system testing uses a buzzer and LED to detect conductive material passing through. Conductive sensor test results showed that the instrument can detect 6 conductivity materials such as stainless steel, aluminum, steel, zinc, copper, and tin. The average response time to detect conductive material is 3 seconds, the average ADC value of the conductive material is 0.55 . The test results also successfully send information and data to the Blynk application so that it can be monitored online. 


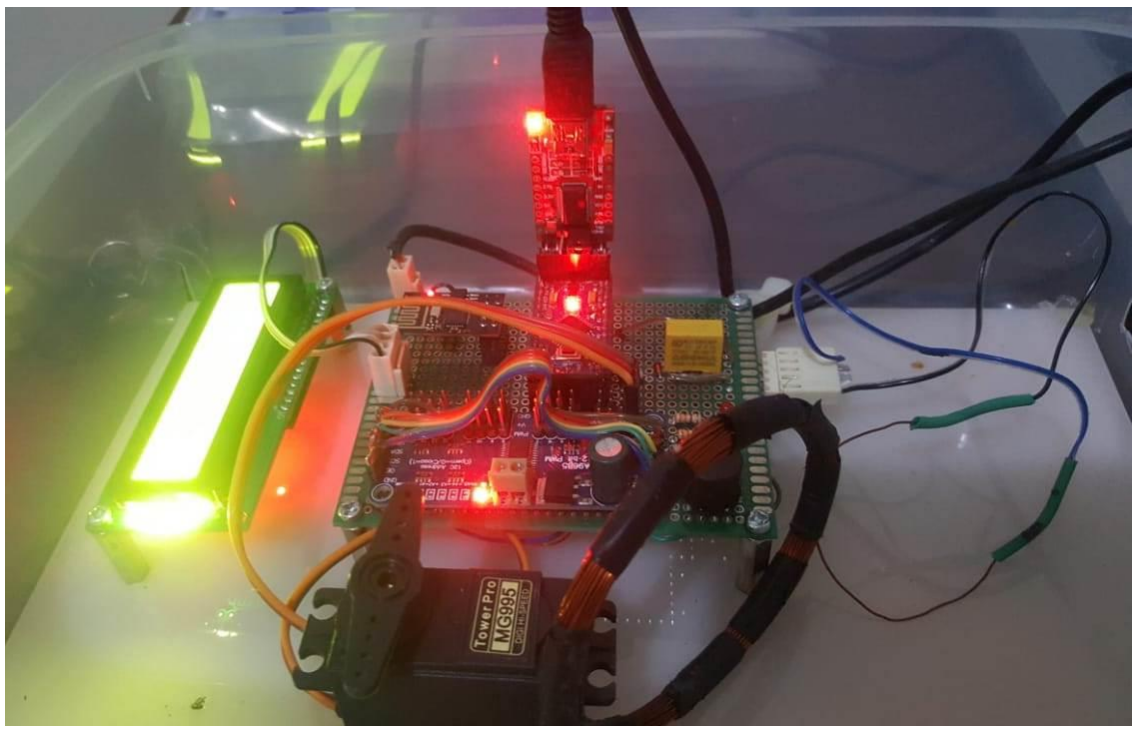

Figure 8. Conductive material detection device prototype

\section{REFERENCES}

[1] N. Lokmanulhakim, et al., "Experiment study of using parallel plate sensor for the detection of conductive material," International Journal of Electrical and Computer Engineering (IJECE), vol. 9, no. 6, pp. 5628-5635, 2019.

[2] M. Shaban, A. G. A. Hady and M. Serry, "A New Sensor for Heavy Metals Detection in Aqueous Media," IEEE Sensors Journal, vol. 14, no. 2, pp. 436-441, 2014.

[3] M. Shaban and M. Serry, "A new sensor for heavy metals detection in aqueous media," in SENSORS, 2012 IEEE, Taipei, 2012, pp. 1-4, doi: 10.1109/ICSENS.2012.6411184.

[4] J. Lai, et al., "Porous silicon based infrared photonic-sensor for high sensitive heavy metal ion detection," in 2015 Transducers - 2015 18th International Conference on Solid-State Sensors, Actuators and Microsystems (TRANSDUCERS), Anchorage, AK, 2015, pp. 1476-1478.

[5] J. W. Lim, et al., "Chemostat-like microfluidic platform for highly sensitive detection of heavy metal ions using microbial biosensors," in 2015 IEEE SENSORS, Busan, 2015, pp. 1-3.

[6] S. Maher, et al., "Portable fluorescent sensing array for monitoring heavy metals in water," in 2016 IEEE SENSORS, Orlando, FL, 2016, pp. 1-3.

[7] K. Bhavsar, et al., "Fibre optic sensor to detect heavy metal pollutants in water environments," OCEANS 2017 Aberdeen, Aberdeen, 2017, pp. 1-4, doi: 10.1109/OCEANSE.2017.8084982.

[8] S. Wang, et al., "FET Based Heavy Metal Ion Sensor to Detect Mercury Ion from Waste Water," in 2019 20th International Conference on Solid-State Sensors, Actuators and Microsystems \& Eurosensors XXXIII (TRANSDUCERS \& EUROSENSORS XXXIII), Berlin, Germany, 2019, pp. 1270-1273.

[9] M. Gartner, et al., "Electrochemical Sensors for Detection of Different Ionic Species (Nitrites/Nitrates and Heavy Metals) in Natural Water Sources," in 2018 International Semiconductor Conference (CAS), Sinaia, 2018, pp. 329332, doi: 10.1109/SMICND.2018.8539739.

[10] S. Dong, et al., "Evenness Detection Method for Sample Distribution of Agricultural Heavy Metal in the Fragmented. Regions," in 2018 7th International Conference on Agro-geoinformatics (Agro-geoinformatics), Hangzhou, 2018, pp. 1-4, doi: 10.1109/Agro-Geoinformatics.2018.8476015.

[11] P. Dhara, et al., "Optical Fiber-Based Heavy Metal Detection Using the Localized Surface Plasmon Resonance Technique," IEEE Sensors Journal, vol. 19, no. 19, pp. 8720-8726, 2019, doi: 10.1109/JSEN.2019.2921701.

[12] J. Hwang, et al., "Enhanced Electrochemical Detection of Multiheavy Metal Ions Using a Biopolymer-Coated Planar Carbon Electrode," IEEE Transactions on Instrumentation and Measurement, vol. 68, no. 7, pp. 2387-2393, 2019, doi: 10.1109/TIM.2019.2908045.

[13] F. Silaban, S. Budiyanto, and W. Raharja, "Stepper motor movement design based on FPGA," International Journal of Electrical and Computer Engineering (IJECE), vol. 10, no. 1, pp. 151-159, 2020, doi: 10.11591/ijece.v10i1.

[14] A. H. Ziadat, A. Jiries, and I. Alojail, "Accumulation of Heavy Metals on Soil Irrigated with Treated Wastewater at Al al-Bayt University-Jordan," in 2019 Advances in Science and Engineering Technology International Conferences (ASET), Dubai, United Arab Emirates, 2019, pp. 1-6, doi: 10.1109/ICASET.2019.8714348.

[15] A. Bamshad and H. J. Cho, "Digital Microfabrication on Paper and Cloth for Heavy Metal Detection and Remediation," in 2019 20th International Conference on Solid-State Sensors, Actuators and Microsystems \& Eurosensors XXXIII (TRANSDUCERS \& EUROSENSORS XXXIII), Berlin, Germany, 2019, pp. 685-688, doi: 10.1109/TRANSDUCERS.2019.8808487.

Int J Rob \& Autom, Vol. 9, No. 4, December 2020 : 292 - 299 
[16] M. Zhou and A. Xiang, "Simulation of all-digital metal detector," Computer Simulation, vol. 30, no. 9, pp. 208212, 2013.

[17] J. Svatoš, J. Vedral, and T. Pospisil, "Advanced Instrumentation for Polyharmonic Metal Detectors," IEEE Transactions on Magnetics, vol. 52, no. 5, pp. 1-4, May 2016.

[18] C. A. Antoun, et al., "Balanced Metal Detector Based on Optimized Frequencies and Spatial Phase Profile Responses to Differentiate Metal Rods,” IEEE Magnetics Letters, vol. 8, pp. 1-5, 2017.

[19] Y. Zhao, et al., "On the Low-Frequency Electromagnetic Responses of In-Line Metal Detectors to Metal Contaminants," IEEE Transactions on Instrumentation and Measurement, vol. 63, no. 12, pp. 3181-3189, 2014.

[20] S. Bai and Y. Bai, "High Precision Algorithm of Metal Detector Based on Balance Coil," in $201821 s t$ International Conference on Electrical Machines and Systems (ICEMS), Jeju, 2018, pp. 684-687.

[21] L. S. Kharangate, N. Guinde, and A. Tamba, "A novel approach for metal detection in food using curve fitting technique," in 2017 2nd IEEE International Conference on Recent Trends in Electronics, Information \& Communication Technology (RTEICT), Bangalore, 2017, pp. 1867-1871.

[22] B. Kim, et al., "Pulse-induction metal detector with time-domain bucking circuit for landmine detection," Electronics Letters, vol. 51, no. 2, pp. 159-161, 2015.

[23] D. Ambruš, D. Vasić, and V. Bilas, "Model-based target classification using spatial and temporal features of metal detector response," in 2015 IEEE Sensors Applications Symposium (SAS), Zadar, 2015, pp. 1-6.

[24] S. Kurachi, et al., "High-frequency induction heating for tiny foreign metals," in 2015 9th International Conference on Power Electronics and ECCE Asia (ICPE-ECCE Asia), Seoul, 2015, pp. 2203-220.

[25] J. Kim, D. Kim and Y. Park, "Free-Positioning Wireless Power Transfer to Multiple Devices Using a Planar Transmitting Coil and Switchable Impedance Matching Networks," IEEE Transactions on Microwave Theory and Techniques, vol. 64, no. 11, pp. 3714-3722, 2016.

\section{BIOGRAPHIES OF AUTHORS}

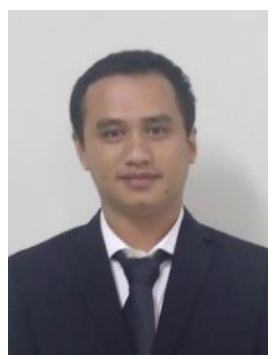

Freddy Artadima Silaban received his Master of Engineering (MT) degree in Electrical Engineering, Information Technology Specialization, Gunadarma University, Depok, 2016. He currently teaches at Universitas Mercu Buana, Jakarta (Indonesia). The focus of the research is an embedded system using control devices such as the FPGA, Arduino, and NodeMCU Modules. As well as IC design research using Xilinx ISE.

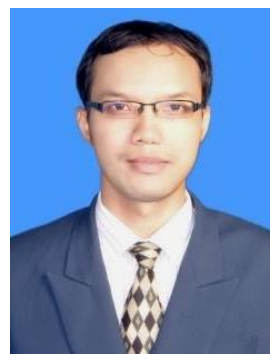

Setiyo Budiyanto is an Associate Professor in Electrical Engineering, Universitas Mercu Buana. He received his Ph.D. in Electrical Engineering, Universitas Indonesia (2016). Currently he is active as a Lecturer at Universitas Mercu Buana, Jakarta (Indonesia). He conducts some research in the fields of Digital - Advanced Wireless Communication (D-AWC).

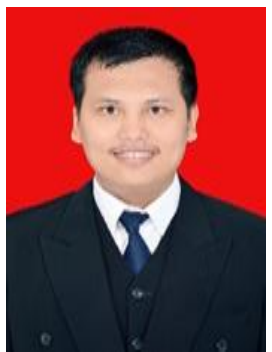

Lukman Medriavin Silalahi received his Master of Engineering (MT) degree in Electrical Engineering, Microwave Technology, Universitas Mercu Buana, Jakarta, 2017. He currently teaches at Universitas Mercu Buana, Jakarta (Indonesia). The focus of research is mobile telecommunications and embedded systems. 